\title{
Synthesis of 1-(2-(piperidin-1-yl)ethyl)-1H-pyrrole-2-carbaldehyde
}

\author{
Caolin Wang ${ }^{1}$, Yuanbiao Tu${ }^{1}$, Jiaqian $\operatorname{Han}^{1}$ and Yuping Guo, a
}

${ }^{1}$ School of Pharmacy, Jiangxi Science \& Technology Normal University, Nanchang 330013, China a305560258@qq.com

Keywords: $1 H$-pyrrole-2-carbaldehyde; Synthesis

\begin{abstract}
H-pyrrole-2-carbaldehyde 4a-b is a new aqueous solubility aldehyde as an important intermediates of small molecule anticancer drugs. In this work, a rapid synthetic method for target compounds $4 \mathrm{a}-\mathrm{b}$ was established. The compound $4 \mathrm{a}-\mathrm{b}$ was synthesized from the commercially available pyrrole through three steps including acylation and two steps nucleophilic substitution. The structure was confirmed by MS and ${ }^{\mathrm{I}}$ HNMR. Furthermore, the synthetic method was optimized. The total yield of the three steps was $65 \%$.
\end{abstract}

\section{Introduction}

$1 \mathrm{H}$-pyrrole-2-carbaldehyde (1) is a key intermediate and has a wide range of applications in the pharmaceutical and chemical fields. 2-((1H-pyrrol-2-yl) methylene) hydrazine-1-carbothioamide (2) was designed and synthesized basing on 1H-pyrrole-2-carbaldehyde [1-3]. 2-((1-methyl-5-(2-(trifluoromethyl)phenyl)-1H-pyrrol-2-yl)methylene)hydrazine-1-carboximidamid e(3) was synthesized according to 1-methyl-1H-pyrrole-2-carbaldehyde by Gilles Gaubert, Fabio Bertozzi et al[4-6]. Wei Gan, Patrick J. Moon [7-9] et al. Used 1-methyl- 1H-indole-

2-carbaldehyde as a key intermediate to synthesize $(3 \mathrm{aS}, 4 \mathrm{R}, 7 \mathrm{~S}, 7 \mathrm{aR})-1-(1-(1 \mathrm{H}-\mathrm{indol}-2-\mathrm{yl})$ ethylidene)-3-oxooctahydro -4,7-methanoindazol-1-ium-2-ide[10] (4), which were stirred together at $120^{\circ} \mathrm{C}$ temperature for 3 hours. The Structures of the intermediate active compounds were shown in Fig. 1

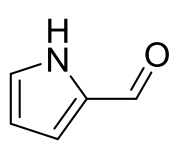

1

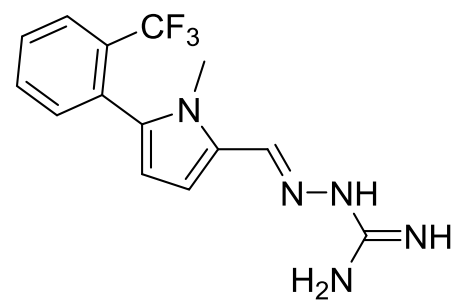

3
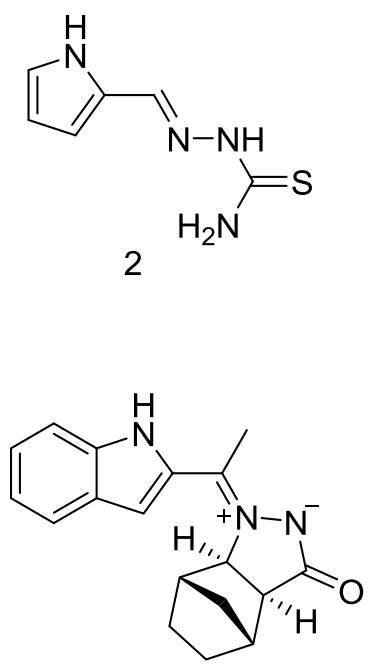

4

Figure 1. Structures of the intermediate active compounds containing the intermediate

As have been reported, 1H-pyrrole-2-carbaldehyde derivations was an important

intermediate for synthesis those active compounds. In this paper, a new series of 1-(2-(piperidin-1-yl) ethyl)-1H-pyrrole-2-carbaldehyde 4a-b was synthesized. Our synthetic method of $4 \mathrm{a}-\mathrm{b}$ was optimized based on the previous study. In the second step, we replaced 1,2-bromoethane with 1-chloro-2-bromoethane, giving a yield of $96 \%$, make it more suitable for industrial production. Structure of the target compound 4a-b shown in Fig. 2. 


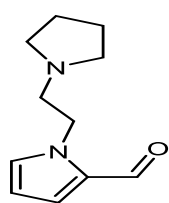

$4 \mathrm{a}$

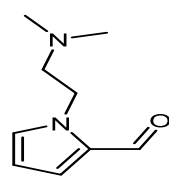

$4 b$

Figure 2. Structure of the target compound $\mathbf{4 a - b}$

\section{Materials and Methods}

All melting points were obtained on a Büchi Melting Point B-540 apparatus and were uncorrected. NMR spectra were performed using Bruker $400 \mathrm{MHz}$ spectrometers with TMS 210 as an internal standard. Mass spectra (MS) were taken in ESI mode on Agilent 1100 LC-MS. All the materials were obtained from commercial suppliers and used without purification, unless otherwise specified. Yields were not optimized. TLC analysis was carried out on silica gel plates GF254.

\section{Synthesis of Compounds}

The structures and the synthetic route were shown in Scheme 1.

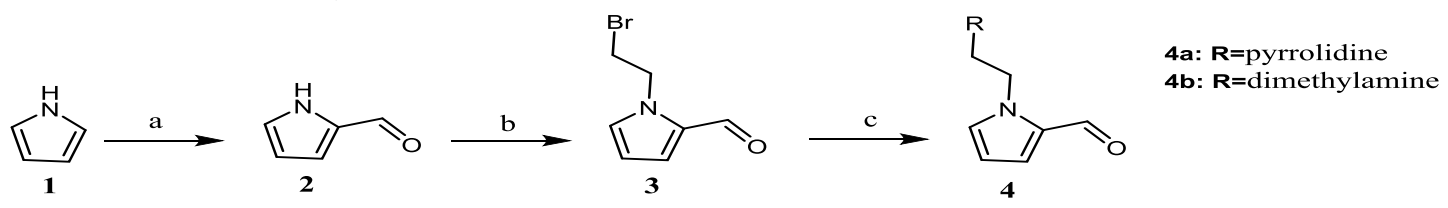

Scheme 1. The synthetic route of compound $4 \mathrm{a}-\mathrm{b}$

Reagents and Conditions: (a) DMF, $\mathrm{POCl}_{3}, \mathrm{CH}_{3} \mathrm{CHCl}_{2}, \mathrm{CH}_{3} \mathrm{COONa}, \mathrm{H}_{2} \mathrm{O}$; (b) DMSO, 1-chloro-2-bromoethane, $\mathrm{K}_{2} \mathrm{CO}_{3}$; (c)DMF,

Preparation for $\mathbf{1 H}$-pyrrole-2-carbaldehyde (2). $N, N$-dimethylformamide $(2.15 \mathrm{~g}, 30.0 \mathrm{mmol})$ in an ice bath was slowly treated with $\mathrm{POCl}_{3}(3.38 \mathrm{~g}, 30.0 \mathrm{mmol})$. The ice bath was removed, and the mixture was stirred for $5 \mathrm{~min}$. The ice bath was replaced, and anhydrous 1,1-dichloroethane (6.8 $\mathrm{mL}$ ) was added, followed by a solution of pyrrole (1) $(1.25 \mathrm{~g}, 18.4 \mathrm{mmol})$ in 1,1-dichloroethane (6.8 $\mathrm{mL}$ ) over $30 \mathrm{~min}$. The mixture was refluxed for $15 \mathrm{~min}$ and then cooled to room temperature. A saturated aqueous $\mathrm{NaOAc}$ solution $(6.9 \mathrm{~g}$ of $\mathrm{NaOAc}$ in $15 \mathrm{~mL}$ of deionized water) was added, and the mixture was refluxed for $15 \mathrm{~min}$. The mixture was cooled to room temperature and then was diluted with diethyl ether. The mixture was washed with saturated aqueous $\mathrm{NaHCO}_{3}$ solution. The organic layer was dried $\left(\mathrm{Na}_{2} \mathrm{SO}_{4}\right)$ and concentrated to yield a brown solid $(2.01 \mathrm{~g}, 93 \%)$ : $\mathrm{mp}$ $38-40{ }^{\circ} \mathrm{C}$;

${ }^{1}$ HNMR $\delta$ 6.44-6.54 (m, 1H), 7.31-7.24 (m, 1H), 7.18-7.20 (q, 1H),9.51 (d, J = 2.6 Hz, 1H), $10.65(\mathrm{dd}, \mathrm{J}=98.4 \mathrm{~Hz}, \mathrm{~J}=24.0 \mathrm{~Hz}, 1 \mathrm{H})$;

\section{Preparation for 1-(2-bromoethyl)-1 H-pyrrole-2-carbaldehyde} 1H-pyrrole-2-carbaldehyde (2) was dissolved in DMSO (10mL). NaH $(2.53 \mathrm{~g} \mathrm{60 \% ,6.0mmol)} \mathrm{was}$ slowly added to the solution and stirred for $30 \mathrm{~min}$ at room temperature. Then 1-chloro-2-bromoethane $8 \mathrm{~g}(42.5 \mathrm{mmol})$ was added dropwise and refluxed for $1 \mathrm{~h}$ at $110{ }^{\circ} \mathrm{C}$. The reaction was monitored by thin-layer chromatography (TLC). The reaction solution was added to saturated $\mathrm{NaCl}$ and extracted with ethyl acetate. The organic layer was dried over anhydrous $\mathrm{Na}_{2} \mathrm{SO}_{4}$ and concentrated under a reduced pressure to afford 1-(2-bromoethyl)-1H-pyrrole-2-carbaldehyde (3) as yellow liquid(3.53 g, 96\%).

Preparation for 1-(2-(piperidin-1-yl) ethyl)-1H-pyrrole-2-carbaldehyde (4). A mixture of 1-(2-bromoethyl)-1H-pyrrole-2-carbaldehyde (3.53 g, 17.7mmol), Piperidine (3.0 g, 35.4mmol) and DMF $(20 \mathrm{~mL})$ was heated and stirred for $24 \mathrm{~h}$ at $125{ }^{\circ} \mathrm{C}$, and the reaction was monitored by TLC. The mixture was added to saturated $\mathrm{NaCl}$, extracted with ethyl acetate. The combined organic layer 
was dried over anhydrous $\mathrm{Na}_{2} \mathrm{SO}_{4}$ and was concentrated under a reduced pressure to obtain 1-(2-(piperidin-1-yl)ethyl)-1 $H$-pyrrole-2-carbaldehyde (4) as yellow liquid (3.0g, 85\%) . ${ }^{1} \mathrm{HNMR} \delta \mathrm{H}$ (400 MHz, DMSO) $9.25(1 \mathrm{H}, \mathrm{s}), 7.72(1 \mathrm{H}, \mathrm{d}), 6.78(1 \mathrm{H}, \mathrm{d}, \mathrm{J} 3.2), 5.98(1 \mathrm{H}, \mathrm{d}), 4.14(2 \mathrm{H}, \mathrm{t}, \mathrm{J}$ 6.6), $2.44(2 \mathrm{H}, \mathrm{t}, \mathrm{J} 6.6), 2.21(4 \mathrm{H}, \mathrm{t}), 1.41(4 \mathrm{H}, \mathrm{t})$.

\section{Conclusions}

In conclusion, 4a-b were synthesized from the commercially available pyrrole through three steps including acylation and nucleophilic substitution. Due to optimization of the synthesis conditions of the target compound $4 \mathrm{a}-\mathrm{b}$, the purity of the product was much more higher. Its structure was confirmed by $1 \mathrm{HNMR}$ spectrum.

\section{Acknowledgments}

We gratefully acknowledge the generous support provided by Project supported by Science and Technology Project Founded by the Education Department of Jiangxi Province (No. GJJ150813) and College Students' Science and Technology Innovation Project of Jiangxi Province.

\section{References}

[1] C.E. Griffiths, L.J. Finkel, C.M. Ditre, T.A. Hamilton, C.N. Ellis, J. Voorhees, Br. J.Dermatol. 129 (1993) 415e421.

[2] Kim Y J, Uyama H. Tyrosinase inhibitors from natural and synthetic sources: structure, inhibition mechanism and perspective for the future[J]. Cellular and Molecular Life Sciences CMLS, 2005, 62(15): 1707-1723.

[3] Gaubert G, Bertozzi F, Kelly N M, et al. Discovery of selective nonpeptidergic neuropeptide FF2 receptor agonists[J]. Journal of medicinal chemistry, 2009, 52(21): 6511-6514.

[4] Okombi S, Rival D, Bonnet S, et al. Analogues of N-hydroxycinnamoylphenalkylamides as inhibitors of human melanocyte-tyrosinase[J]. Bioorganic \& medicinal chemistry letters, 2006, 16(8): 2252-2255.

[5] Liu J, Yi W, Wan Y, et al. 1-(1-Arylethylidene) thiosemicarbazide derivatives: A new class of tyrosinase inhibitors[J]. Bioorganic \& medicinal chemistry, 2008, 16(3): 1096-1102.

[6] Yi W, Cao R, Chen Z, et al. Rational design and synthesis of 4-O-substituted phenylmethylenethiosemicarbazones as novel tyrosinase inhibitors[J]. Chemical and Pharmaceutical Bulletin, 2010, 58(5): 752-754.

[7] Battaini G, Monzani E, Casella L, et al. Inhibition of the catecholase activity of biomimetic dinuclear copper complexes by kojic acid[J]. JBIC Journal of Biological Inorganic Chemistry, 2000, 5(2): 262-268.

[8] Yamazaki S, Itoh S. Kinetic evaluation of phenolase activity of tyrosinase using simplified catalytic reaction system[J]. Journal of the American Chemical Society, 2003, 125(43): 13034-13035..

[9] Yi W, Cao R, Wen H, et al. Discovery of 4-functionalized phenyl-O-尾-D-glycosides as a new class of mushroom tyrosinase inhibitors[J]. Bioorganic \& medicinal chemistry letters, 2009, 19(21): 6157-6160.

[10] Gan W, Moon P J, Clavette C, et al. Synthesis and Reactivity of Unsymmetrical Azomethine Imines Formed Using Alkene Aminocarbonylation[J]. Organic letters, 2013, 15(8): 1890-1893. 